\title{
Business Schools: Generators of Skills for Entrepreneurs
}

\author{
Maria Teresa Freire Rubio ${ }^{1, *}$, Ana I. Rosado Cubero² \\ ${ }^{1}$ Department of Economics, ESIC Business \& Marketing School, Spain \\ ${ }^{2}$ Department of History and Economic Institutions I, Faculty of Commerce, Complutense University, Spain
}

Copyright (C) 2015 by authors, all rights reserved. Authors agree that this article remains permanently open access under the terms of the Creative Commons Attribution License 4.0 International License

\begin{abstract}
The purpose of this paper is to present the methodology and results of a study on the role played by higher education institutions - universities and business schools from different master's degree programs-, when responding to the demands of potential entrepreneurs who are seeking to get the tools and develop the skills necessary to eventually become successful. We have proposed the use of a methodology based on a survey of students currently enrolled in master's programs, to get to know their entrepreneurial drive, the tools they consider appropriate to achieve their degrees and what they think is the best way to start a new business. Also the ultimate goal of the study is based on the results: making a proposal of academic content, theoretical and / or practical as deemed necessary, to add to these programs in order to improve the training required by future entrepreneurs.
\end{abstract}

Keywords M13 - New Firms, Start-ups, I23 - Higher Education and Research Institutions, A23 - Graduate

\section{Introduction}

Historically, both universities and business schools have aimed to be places which provide useful tools for future entrepreneurs and business men or women, so that young students acquire, from their training in these institutions, the necessary skills and knowledge to learn how to be successful in their jobs. In fact, the Spanish 2012 GEM report [1] evidences the lack of entrepreneurial education and training contents in specific business administration and management programs. Ultimately, their role and good work will be rewarded by the success of the knowledge acquired by the students during this training. Within this area, our analysis has been focused specifically on master's programs developed by business schools, for they have a great tradition in developing more specific trainings based on business management and enterprising skills.

Having thus aimed to see the correlation between the training acquired in these master's programs and the determining variables of entrepreneurship, a research project was raised at ESIC Business \& Marketing School. Its Department of Research approved the implementation of a research project, which aimed to identify successful entrepreneurs' features or qualities and also the master's program training ones, since these programs can help encourage those entrepreneurial skills. It was decided to conduct an analysis on a survey made from two points of view and addressed to two different audiences and profiles:
A. Analysis of the variables that influence entrepreneurship through a predictive model of Artificial Neuronal Networks.

In this case, the survey is aimed at people who "already engaged": The sample was obtained from all the "start-ups" created inside incubators, within the network of Madrid Emprende. These business incubators are characterized by direct connection and, in many cases their own origin, linked to a university in Madrid. The role played in this case by the university, is to provide technical, legal and financial support to emerging entrepreneurs. Thus there are significant cost savings associated with the start of any business initiative. Business incubators provide entrepreneurs and advise them, mainly when they are looking for initial capital to start a business, and afterwards, they offer them constant support through the universities.

We can therefore conclude this introduction to this study, with the role of incubators fostering entrepreneurship and the role of the university, participating in the incubators project and transferring knowledge from the university professors to the future incubator entrepreneurs, advising and assisting them on the creation of new companies.

In this part of the study, we work with the survey of 106 entrepreneurs located in different business incubators, and the results obtained on the survival of these start-ups, keeping in mind that survival is measured as a waiting period of at least two years. At present-day, after the collection and processing of all data, surveys are in their first year evaluation process.

\section{B. Determinants of entrepreneurship: skills and tools developed in Master's Programs.}

The survey in this case is aimed at potential entrepreneurs, who, at the time of data collection, are studying a master's 
program which has been selected for the sample.

Throughout this article we will focus on the development of this part of the study, explaining the methodology used for development.

The aim of this survey is double, on the one hand, seeing the evolution of companies who are already in a business incubator, and therefore they have already taken the initiative to launch and, on the other hand, comparing the two surveys (business incubator entrepreneurs and master's program students) and observing the similarity among entrepreneurs already underway and potential entrepreneurs (current master's students). That is, tracking the start-ups in order to check which of them achieve to become a well-established company.

We can get relevant information from the above comparison, like the training relationship between these students' Master and their degree of entrepreneurship, and then, we can compare both, master students and the common characteristics of current entrepreneurs.

\section{Economic Literature Review on Entrepreneurship}

The research project seeks to shed light on the appropriateness of allocating public grant start-ups, also known in Spanish by the English word "start-ups", and, at the same time, to stand out how conclusion would be promoting innovation through university. We will analyse the tradition of helping start-ups through the main lines of the history of economic thought, regarding the suitability of a particular type of public grants or action. Our research was focused on businesses defining the variables that shape entrepreneurs as eligible subjects; and concluded with a proposal aimed at students from a specific university predisposed to entrepreneurship which allowed them to develop the skills necessary to make an original idea become successful.

The tradition of this line of thought is connected with the protection that any state should keep on their industry when products come from overseas, as well as with the theory of international trade. Among the classical economists, such as Jean Baptiste Say [2] and John Stuart Mill [3], few suspected to be disposed to government intervention in the market economy, they do not hesitated to say that while aid is brief, states must help their new businesses or start-ups, bearing in mind that classical economy compared business life with the human life cycle. J.B. Alfred Marshall [4], it had to be him, argues that the more firms are in any market, the more the competition increases and the lower the prices are, creating welfare for consumers. However, it seems convenient to help start-ups, and, using Marshall's owns words: "until they achieve sufficient economies of scale to survive within its market." [4, p 265]

In the late twentieth century emerges an economic theory known as the theory of human capital accumulation, which argues that companies not only accumulate physical capital if they do the same with human capital; therefore, much of this capital has been acquired by the method of "learning by doing". This idea could be transferable to university education because it allows teaching students from a more theoretical training to a more practical one. Business schools collect this experience and make it their own, training professionals using more tools and skills; abandoning the old way of teaching.

The idea of universities improving their teaching tools, including training for entrepreneurs, joined the project to launch business incubators, where students learn by doing this activity and their companies begin to take shape with the growth of self-employment (mainly due to the fact that the last millennium began with a crisis). Following the old ideas of the nineteenth century, university incubators try to help start-ups, for example, by promoting them through any municipal corporations. Start-ups should also enjoy some kind of state aid, at least temporarily, without forgetting that market distortion must be minimum.

Curious thing about this initiative is that in the United States [5] incubators and start-ups produce a high rate of return, primarily via taxation, but also through synergies within entrepreneurs working in the same incubator. And the proliferation of all kinds of incubators is a booming business. With them, creating companies is easier. With a little investment, a computer terminal, a conference room, Internet access, authorization to bind links to the activity log, collecting taxes, other bureaucratic clearances, and employing an entrepreneur, you can start a company which shall become an established company.

Once we have a theoretical argument to defend the willingness of helping start-ups, a significant part of the project is to find the best methods for assessing these projects' viability. Universities should make a cost-benefit calculation to check if it's profitable to launch the business incubators. At the beginning, no more than a physical space with several terminals (to be used by students in turns) and a small meeting room. The analysis will include the cost of the advice needed to start the business, which should be offered by university staff, and, on the other hand, obtaining permits access to a more ministerial link used by entrepreneurs. The University will face costs in infrastructure, or reallocation of available spaces, in addition to the costs input (electricity, internet, cleaning, etc.) in order to offer a real incubator for their students.

\section{Methodology}

We pursued a relationship between entrepreneurship and the academic training of future entrepreneurs. For this purpose, we have selected master's programs, where a future entrepreneur can find complementary education to their main training in business administration and also a few questions for a questionnaire, in order to be able to identify entrepreneurship traits among students who are already participating in our master's programs. The methodology and techniques used to achieve this goal will be discussed below. 


\subsection{Development of the Survey}

All literature on the entrepreneurial process, and the characteristics that make an entrepreneur effective [6, p 96], agrees on the fact that the entrepreneur is:

"A person who can generate a new entity or organization by getting, combining and coordinating human, technical, material and financial resources for the purpose of achieving certain goals."

Successful entrepreneurs act effectively, transmitting enthusiasm to the people around them and creating a favourable environment to achieve their goals [7]. This statement is based on three elements proved by experience:

1. Entrepreneurs have net personality traits that constitute a psychological profile, which compels them to start a creative process and transform it taking risks.

2. This profile is associated to certain behaviours that can be trained, which would influence the level of effectiveness or outcome of the venture.

3. The subject's environment affects the magnitude of the enterprise; more and better social opportunities improve the chances of a higher quality and the sustainability of the initiatives.

Learning how to be an effective entrepreneur is a long and complex process that requires a method and practicing the use of certain instruments. First, it is necessary to develop cognitive, emotional and social techniques Second, the entrepreneur needs certain knowledge and skills to express these techniques with an effective way; this is what we call entrepreneurial skills.

\section{Entrepreneurial Skills}

Natural Skill + + Technical Knowledge and Systematic Training

Other studies have also shown that creativity, innovation and controlled-risk taking are the traits that define every entrepreneurial profile "per se" and the critics to the business entrepreneur. We could also name another set of attributes that are commonly associated to an entrepreneurial profile in a greater or lesser extent, although these features are also present in non-entrepreneurs, trained or developed, which influences the level of success of the venture. Research in this area, combined with the practical knowledge, leads us to postulate that entrepreneurs have an effective behaviour associated with five main traits or skills of their personality:

1. Strong self-awareness and self-confidence.

2. High motivation for achievement.

3. True visionary and optimistic.

4. Planning and organization capacity.

5. Effective communicator and network generation supporter.

Based on these premises, the survey was developed for graduate students in order to:

1. Verify the presence of a certain natural ability that promotes entrepreneurship.

2. Check if they aim for some kind of specific training in order to acquire skills that will enable them to be more confident in creating businesses. It is not to be forgotten that undertaking a project is also a combination of innovation and risk, even if this is obviously a measured risk.

3. Check whether these natural ability, knowledge and training, are boosted by an entrepreneurship background in the family.

The objective of this survey and its results we get is better training in entrepreneurship for students enrolled in postgraduate programs and master. To achieve the objective of the survey questions we try to collect student's profile whose choose some training program. Thus, the results should show us the profile of potential entrepreneurs, at the same time we could propose improvement of these programs; in order to develop skills and knowledge expected by the students and help them how to improve their entrepreneurship successfully.

The relationship of variables or items used in the design of the quick is shown in Table 1, which includes a description of each of the variables.

Table 1. Questionnaire

\begin{tabular}{|c|c|}
\hline 1 & The knowledge acquired in my education, both undergraduate and graduate, have helped me in creating a business. \\
\hline 2 & Promoting management skills received during my training, I have generated enough confidence to take on responsibilities and face challenges. \\
\hline 3 & I own enough personal initiative to undertake projects. \\
\hline 4 & I own skills to manage teams \\
\hline 5 & I have no problem in leading risk situations within the work (skill conflict management). \\
\hline 6 & I assume so self-critical failures or setbacks at work and learn from them. \\
\hline 7 & When taking a risk, I value the chances of success as failure, before making a decision or undertake a project. \\
\hline 8 & Easily visualized or detected new market opportunities that can turn into entrepreneurship. \\
\hline 9 & Continuing education is key when taking on new professional challenges, brings tranquility to act and face challenges. \\
\hline 10 & The entrepreneur is the sum of skills and knowledge. \\
\hline 11 & I'm persevering in achieving the objectives set and able to go the extra mile to achieve them. \\
\hline 13 & I am clear in defining the objectives and planning, designing consistent plans for achieving them. \\
\hline 14 & I can generate empathy in my environment to build networks of support for my projects. \\
\hline 15 & I manage and coordinate efficiently the resources used to achieve the objectives: time, money, human resources, etc. \\
\hline
\end{tabular}


The data collection was performed using a Likert scale of seven points: the degree of agreement or disagreement that subjects have for each sentence. Ratings:

1. Strongly disagree

2. Moderately disagree

3. Somewhat disagree

4. Neither agree nor disagree

5. Agree a little

6. Moderately agree

7. Strongly agree

Participants completed the survey on basic demographic data: age, sex, nationality, place of residence, education level and current employment status.

\subsection{Justifying the Selection of Future Entrepreneurs}

The majority of the sampling has been collected from the master's program of ESIC Business \& Marketing School, due to the fact that this school represents a significant weight within the education Spanish market. At the same time, the classical ESIC training for Entrepreneurship is very relevant in Spain and, additionally, ESIC has the advantage of having different subsidiary schools throughout the Spanish territory. All together allow us to get enough information to study data, and to draw conclusions at will; while offering us different data to distinguish between diverse geographical areas. For instance, defining a common variable between future entrepreneurs or even categorize some media or entrepreneurship based on social characteristics of different areas. In addition, in the sample survey, we have included participants of two specific Master's programs in entrepreneurship taught at two public universities of Madrid: the Faculty of Commerce (Complutense University of Madrid, UCM) and the Faculty of Social and Legal Sciences (Rey Juan Carlos University of Madrid, URJC).

In the final sample a total of 387 questionnaires have been collected from which we try to obtain indicative results on the skills and knowledge among participants studying a master's program in order to promote and categorize the profile of future entrepreneurs.

\subsection{Analysis of the Variables}

The development of computer technology over the last two decades has made possible extraordinary advances in the development of techniques or methods aimed to multivariate data analysis [8], an analysis that bivariate and univariate statistical studies have been unable to get.

The basic objective of the analysis is to analyse and summarize multivariate large amounts of data and variables, according to certain objectives in order to obtain valid information that allows a better understanding of the phenomenon under study. The simplified representation of large amounts of data has been configured as a remarkable tool for synthesis. Besides, its application domain has expanded exponentially since computer tools developed and made possible the individual treatment, storage and acquisition of information.

The Principal Component Analysis (PCA) is a statistical technique for synthesising information or reducing the size (number of variables). That is, to a file or database with many variables, the target will be reduced to fewer, losing as minimum information as possible. The new factors or principal components are a linear combination of the original variables, and will also be independent. A key aspect of the PCA is the interpretation of the factors, since it is not given $a$ priori, but will be deducted after observing the relationship of the factors with the original variables. It will be vital to have knowledge on the subject under investigation. Another important aspect to consider is that a PCA makes sense if there are high correlations between variables, as this is indicative that there is redundant information and thus, few factors explain much of the total variability. A higher variance incorporated into each of the components, means that it contains a greater amount of information.

\section{A. Obtaining the Components that Build an Entrepreneur's Traits}

After an initial descriptive analysis we obtained statistics for the study of the adequacy of the sample to the model. We can see that the sampling adequacy for this analysis is not only desirable, but also fits really well with the data, as the measure of sampling adequacy Kaiser-Meyer-Olkin (KMO coefficient) [9], which indicates the proportion of variance shared by the analysed variables, it has a value of 0.921 , coefficient very close to a unit which is most recommended for this type of analysis, which indicates a perfect fit of the data to a factor analysis model.

By Bartlett's test of sphericity, as we can see in our analysis, the significance is perfect as it gets the value 0.000 , below the critical level 0.05 , considering the adjustment of variables using the factor analysis suitable, necessary to continue Methodology with ACP.

By applying factor analysis to the original variables, we can find groups of variables with common sense and therefore reduce the number of dimensions needed to explain the answers of the subjects studied. It intends to have the least possible loss of original information. Retained factors are formed by linear combinations of original variables. Reducing the dimension effectively occurs when you select among those factors that have the greatest explanatory power of all the original variables.

From the total, explained variance components are extracted indicating only those who have been retained, in order to expedite and make the reading and the results viewing easier. It has grown from 15 original variables to 3 components, coming to explain more than $60 \%$ of the original total variance.

In our model we can see, and we have said, that from the number three component, the auto value begins to be less than a unit, even in this third component still has a high value, and also the percentage of explained variance amounts accumulated to $60.145 \%$, so we can consider that this may be a value significant enough to believe that there is a sufficient 
number of factors.

From the factor solution, where the correlations (or loadings) between the original variables and each of the factors, it is easy to infer the correspondence between each variable and each of the twelve factors extracted.

Communalities obtained for each of the variables after the extraction can help to check variables such as "knowledge help create business" with a 0.718 commonality, "the skills to manage teams" with a 0.702 or "perseverance to achieve objectives" with a 0.904 . These explain variance in a greater extent according to their participation in the factors or components resulting in the analysis, while variables like "visualize market opportunities", with a 0.357, is less representative for such variance.

\section{B. Justification and Interpreting of the Number of Factors Retained}

Finally it was decided to remove or keep as many factors as auto values greater than a unit the analysed matrix has, being three, in our case, the selected factors. Representing all auto values sorted by size may give you a quick idea of whether the amount of variance associated with each analysis is relevant or otherwise it is just residual.

It should also be noted that the PCA has a Matrix Factorial Rotation Procedure, which transforms the first factorial matrix in another one called rotated factorial matrix, easier to interpret, where rotated factors try each of the original variables to have the nearest possible correlation one with a factor, and near zero correlation with the other, obtaining high correlations with a variable group and low correlations with the rest.

In our study, we use the rotation system Normalisation factors using Varimax rotation [10] converged in 5 iterations, because, as we saw above with three components, they were getting more than $60 \%$ of the explained variance. With the factor solution obtained, where the correlations between the original variables (or saturations) and each of the factors, it is easy to infer the correspondence between each variable and each of the three factors extracted. Note that the original pool variable around the component makes interpretation easier and may determine the name of the component.

We will now rename the components according to the initial variables that incorporate:

Component 1: Contains the most important original variables with factor loadings. This component comprises all attributes found in the survey that show and make a determined and trained entrepreneur to anticipate and plan events so that his/her company or project is less exposed to risk. This will be the component we will call Self-confidence, and which explains just by itself the $39.799 \%$, more than a third, of the total variance, occupying outstandingly the first place before the rest of the components that are being interpreted.

Component 2: Contains only the attributes of the first two original variables with significant factor loadings which may be considered necessary qualities. We call it Proactive, since this factor reflects the knowledge and management skills, alone explaining the $11.616 \%$ of the total variance.

Component 3: Two variables make up this factor: the family atmosphere and entrepreneurial training. With an $8.730 \%$ of the total variance, has called this factor Perseverance.

To examine whether the structure showed variations by gender and/or group repeated the same analysis separately for men and women. The data obtained showed a virtually identical factorial grouping and therefore supports the results described regarding reliability study.

\section{Conclusions}

After the analysis of the variables collected in the survey and knowing all crossings and conclusions on statistics, taken as a relevant variable current employment status, employed or unemployed, and identifying student's willingness to create companies, we have concluded that the currently employed students are those with a higher propensity for entrepreneurship. As we have found, in regard to the type of program attended by students for identifying entrepreneurial spirit, EMBA and GESCO programs are the main chosen, before other more specific training programs.

In the relationship between employment status and interest in starting a business, out of the total number of students who want to create a company $70.6 \%$ are currently employed and $28.9 \%$ were unemployed at the time of answering to the survey. By gender, we conclude that the $64.4 \%$ of women already employed want to start a new company, compared to the $35.6 \%$ of unemployed women. On the men's side, a $74.4 \%$ of company employees are willing to start-up, compared to the $24.8 \%$ of unemployed men which answered that they would like to create a new company.

The highest percentage of employees, men and women, who want to start a business is within an age range between 25 and 35 years, $54.3 \%$ are employed women and 51.9\% employed men. This range age for men is not the most optimal to undertake a business, the best range is older than 35 years: $68.3 \%$. Women, on the other hand, prefer to undertake a business younger, being less than 25 years old: $42.1 \%$.

While $72.7 \%$ of unemployed men over 35 years old would undertake a new business, $66.7 \%$ of women younger than 25 would also risk starting a business.

As for the programs, the most predisposed to create new businesses are the students who chose both programs, EMBA and secondly GESCO (Management and Marketing). EMBA, Executive Master and Business Administration Program, is a peculiar program because experience is required for enrolling the master's program and EMBA are more suitable for people with entrepreneurial spirit. Analyzing by gender, EMBA is chosen mainly by men, while women are more willing to start studying at the GESCO.

Analyzing all students in all programs surveyed, we conclude that $50.8 \%$ want to create a new business whereas 
$49.2 \%$ showed no interest in entrepreneurship. Most of the students who want to undertake a new business are divided in two programs, EMBA and GESCO, and more precisely, $16.5 \%$ of EMBA students say that they want to create companies and only $15.2 \%$ of GESCO's students state the same. Also, these data contrast with the other programs', where students with interest in creating new companies represent $3.9 \%$ in DRHO; $2.9 \%$ in MBA full time, $2.6 \%$ in MBA entrepreneurship (UCM), $1 \%$ in MDF, $1.3 \%$ in MPC, $2.1 \%$ in MRI (URJC); $1.3 \%$ in PSDC; $2.6 \%$ in PSDV and $1.3 \%$ in RRHH.

Revising both gender and programs' students, we want to emphasize that students predisposition for entrepreneurship is given when they are employed, which is paradoxical, because it could be expected that those who are unemployed should be more willing to undertake a new company due to his personal uncertain job situation.

Students more inclined to entrepreneurship are those who have studied social sciences, in contrast with those who have finished technical, humanistic or legal studies. Another important finding in our survey is that those who are currently employed are those who have interest in creating a new company whereas the unemployed show no interest. Despite the above data, we notice that a significant part of the unemployed students (35.7\% of them) do not know or do not answer if they are interested in starting a new business.

The relevant sector in which students, employed and unemployed, would create a company is the service sector. By gender, the survey shows that $72.3 \%$ of employed women would create a company in the service sector, compared to a $58.9 \%$ of men. Among the unemployed, $73.1 \%$ of women would create a company in the service sector while $63.3 \%$ of men would do so.

As a significant variable and highly relevant to our study is the relationship between the sector in which students have developed or are currently developing work experience and the economic sector in which they would be willing to start a new business. This means, how precise knowledge of any sector generates less uncertainty at the moment of undertaking new businesses. This hypothesis is confirmed by the results where the majority of respondents who spent more than three years working in any sector would undertake a new business within this sector, even if they are currently working: $85.1 \%$ of women and $85.6 \%$ of men. On the other hand, the percentages are lower among the unemployed, since men would risk by $60 \%$ when they have more than 3 years' experience but $30 \%$ would try a new firm, just with 1 to 3 years' experience. Women show the opposite, $61.5 \%$ would undertake a business with limited experience of 1-3 years, while $26.9 \%$ would need more than three years of experience to start a business. These percentages are reduced when the experience is less.

These conclusions are, from our point of view the most significant, since the study includes many important variables as we noted at the methodological, and completes a comprehensive analysis of the results obtained with the study, leaving a chance to make a more detailed analysis that would go beyond the scope of this paper. A review of the academic programs should be made after a thorough analysis of the data collected by quiz.

\section{REFERENCES}

[1] GEM. Global Entrepreneurship Monitor, Informe GEM, Madrid, España 2012. Online avaliable from www.gemespaña.es

[2] Say, J.B. Traité d'Economie Politique. Calmann-Levy, France, [1803], 1972.

[3] Mill, J.S. Principles of Political Economy, Liberty Fund, Indianapolis, USA, [1848], 2006.

[4] Marshall, A. Principles of economics of industry. MacMillan and Co., London, [1890] 1948.

[5] Erlewine, M. Measuring Your Business Incubator's Economic Impact: A Toolkit. NBIA Publications. Ohio, USA, 2007. Online available from www.nbia.org/toolkit

[6] Espíritu Olmos, R., \& Sastre Castillo, M.A. La actitud emprendedora durante la vida académica de los estudiantes universitarios. Cuadernos de Estudios Empresariales, vol.17, 95-116. Madrid, España, 2007.

[7] GEM (2008/09/10/11/12713). Global Entrepreneurship Monitor, Informe Ejecutivo GEM, Madrid, España, 2008.

[8] Kinnear, P. R., \& Gray C. D. IBM SPSS Statistics 18 Made Simple. Psychology Press. New York, USA, 2010.

[9] Bryman, A., \& Cramer D. Quantitative Data Analysis with IBM SPSS 17, 18 and 19: A Guide for Social Scientists, Psychology Press, New York, USA, 2011.

[10] Múria Albiol, J., \& Gil Saura, R. Preparación, Tabulación y Análisis de Encuestas para Directivos. ESIC Editorial. Madrid, España, 1998. 